\title{
Teachers' Perception on Using Kio-Kit to Enhance Teaching and Learning STEM Subjects in Zanzibar
}

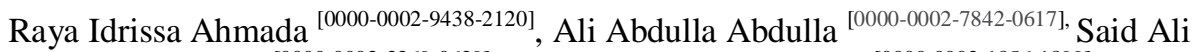 \\ Said Yunus [0000-0003-3369-0629], and Maryam Jaffar Ismail [0000-0002-1856-1899], \\ The State University of Zanzibar, P.O BOX 146, ZANZIBAR \\ www. suza.ac.tz \\ raya.ahmada@suza.ac.tz, ali.abdulla@suza.ac.tz, \\ said.yunus@suza.ac.tz, maryam.ismail@suza.ac.tz
}

\begin{abstract}
In the current situation, teachers are encouraged to use interactive, student-centered approaches than using traditional approaches that mainly focus on 'chalk and talk'. Student-centered approaches, also learner-centered, involve methods of teaching that shift the focus of instruction from the teacher to the student. When these approaches are powered by technology, they can doubly enhance teaching and learning. The most current technology that gains popularity in Africa in teaching and learning process is the Kio-Kit technology which promised to improve the quality of teaching and learning. It is a digital education toolbox which contains different forms of digital contents to help students in their learning process. The box contains 40 Kio tablets in which students use them to access the contents available in the Kio-Kit box. This paper aims to discuss the perception of using this type of technology from school teachers who have been trained intensively to use them to enhance the teaching and learning of STEM subjects. During the exploration, we confirmed that Kio-Kit technology enhances teaching and learning and helps the students gain necessary skills for the 21st century digital era. The results also reveal STEM teachers' readiness to use the Kio-Kit technology in the classroom. Further, the paper describes the challenges encountered during the exploration of Kio-Kit in classroom and some suggestions are proposed.
\end{abstract}

Keywords: Kio-Kits, Digital Classroom, ICT, Student-Centered Learning, STEM for Success, Zanzibar.

\section{Introduction}

With the developments and application of Information and Communication Technologies (ICTs) in education sector, the digital technology has transformed the teaching and learning processes. These changes have been brought forward by the advent of various digital technologies that keep on emerging every now and then. The study by Zolfaghari and Reza [1] concluded that digital technology if used 
appropriately, it can develop better understanding of basic concepts provided for learning.

Currently, there are various forms of digital technologies used to support teaching and learning process such as e-learning platforms like Moodle, Blackboard, Schoology, and Social Medias platform which include services such as Facebook, WhatsApp, and Google Class to mention few.

The teachers should make sure that they encourage students to use ICT as a supplementary tool with the traditional mode of education. The new technologies should make the students learn more and more and not otherwise. This is very important as because technology can be a distraction in education. General view show that students may misuse the technology by wasting most of their time to communicate with friends on social networks and playing online games.

In their study, Forzani and Leu [2] argue that all students must start learning new literacies skills early if they are to gain the skills they will need as adults. This indicates the importance of various skills gained as a result of using technologies in education.

Most of the technologies require the Internet access or other form of connectivity to access different contents available online. Kio-Kit is a digital learning solution engineered in Africa which came as a toolbox with educational contents within it, connectivity and charging capabilities [3]. It has been plotted with features to make it easy to be used in schools in the emerging markets, most of which has poor connection to the Internet and power cut problem. Mark [4] stated that "the thinking behind the Kio-Kit was to narrow the huge educational gap that exists between schools that have access to books, internet and general access to learning content and those that do not.”

\section{Motivation for the study}

The study is part of preliminary results extracted from the STEM FOR SUCCESS ZANZIBAR (S4SZ) project, which is a two-year collaborative project between the State University of Zanzibar (SUZA), Milele Zanzibar Foundation (MZF) and Forum for African Women Educationists (FAWE) ${ }^{4}$. The main goal of the project is to help students especially girls in STEM related field to perform better in their studies, increase their interests and have a clear understanding of STEM subjects and STEM career path right in their early years of studies.

Technology usually provides numerous tools that can be used in and out of the classroom to enhance student learning. In this way, technological tools can dramatically increase student learning, enhance student engagement as well as help teachers come out with creative activities and tasks in teaching their students, Kio-Kit being in the list.

4 The authors gratefully acknowledge the contributions of Wellspring Philanthropic Fund (WPF), Milele Zanzibar Foundation (MZF) and the State University of Zanzibar(SUZA) for supporting the S4Sz initiative in many ways including integrating technology. 
In 2018, the S4SZ project invested about 5 Kio-Kits. Each box has a set of 40 resilient tablets that comes with a server pre-loaded with contents in different categories to help students in English language, literacy in both English and Kiswahili, numeracy, science and general knowledge. Since the Kio-Kit comes with full infrastructure, it is suitable in Zanzibar context where the Internet access is not reliable and the number of textbooks is limited as compared to the number of available students in classes, especially in rural schools.

The Kio-Kit consists of a solid waterproof plastic box, containing 40 toughened tablets in it. Inside the box, there is a server which stores the all the learning materials which are shared to all students' kio-tablets using wireless technology [5]. The box comes with 40 slots to place the kio-tablets after use, and once they are placed they can be charged through the box. To ensure security, the box can also be locked with the tablets inside it and it is very heavy that it is not easy for someone to run away with it.

This digital classroom technology (Kio-Kit) was proposed to be used in Zanzibar classroom to enhance teaching and learning process and promote student-centered approaches in 15 selected schools both in Unguja and Pemba. Hence, a two-day training was conducted to all selected teachers from secondary schools working on of different STEM subjects from the selected schools, in which nine (9) schools from Unguja and six (6) schools from Pemba were involved in the study.

Seventy-five (75) teachers were trained from fifteen (15) selected schools which were part of S4SZ project. The schools involved lower secondary STEM classes (Form one \& Form two). Each school brought 5 teachers (4 STEM subject teachers and 1 head teacher), in other words 60 STEM subject teachers were trained intensively, and 15 headteachers participated in the training for coaching and supporting purposes. The training was conducted in three teacher centres (Centre A, B \& C).

Different activities were prepared for them to understand how they can use Kio-Kit to enhance teaching and learning and moving from "frontal teaching" and "chalk and talk" style of teaching to student-centered approach, in which students' interaction and engagement are highly practiced, making learning relevant and fun.

After the two-intensive day training and exploration of the Kio-Kit box, a further exploration was made to understand teachers' perception on the use of Kio-Kit in enhancing teaching and learning STEM subjects. This is very crucial to know, as the teachers are expected to utilize the technology to the fullest to explore more creative ways of making education interactive, fun to motivate the students, change their mindset on STEM related subjects in order to improve learning.

\section{Objectives}

The study objectives were as follows: -

1. To highlight how Kio-Kit was planned to be used for enhancing teaching and learning STEM subjects in Zanzibar lower secondary classes (Form One and Form Two) 
2. To analyse teachers' perception of using Kio-Kits from those teachers who has been trained to use it in order to improve their teaching and learning

3. To identify challenges encountered during the exploration and the use of Kio-Kit in classroom situation

4. To propose the way forward for technology enhancement in teaching and learning process as expected.

\section{$4 \quad$ Methodology}

Since Kio-Kit is a new technology to the most of the teachers participated in this study, the main aim was to find how far they perceive this technology, and to accomplish that aim different factors were considered during the study.

\subsection{Study Design}

To obtain rich and detailed information needed to document how teachers were exploring and using Kio-Kit for teaching, both qualitative and quantitative data were collected. At each teacher's centre (A, B and C), an online survey was given to both STEM teachers, Headteachers or Assistant Headteachers to complete it to check technology familiarity and uses. STEM teachers were selected based on the assumption that the successful integration of technology can transform STEM classes.

\subsection{Data Collection}

The data were collected from a two days intensive training on the Kio-Kit technology for the STEM teachers teaching Form I and Form II classes from both Unguja and Pemba (Zanzibar). A manual for Kio-Kit for teachers was prepared and used in the training as a guide. The manual was broken down into eight (8) modules explaining what a Kio-Kit is, why it is used, how it works and how it can be integrated into the classroom situation. In addition to that, the teachers were also asked to explore the relevance and applicability of the contents available in the Kio-Kit.

After the training the link to the questionnaire which was prepared using Google Form was shared to both the participants who participated in the training. The teachers were encouraged to fill the form by sending several reminders through WhatsApp.

\subsection{Participants}

Out of sixty (60) STEM trained teachers, thirty-five (35) responded to the online questionnaire, twenty-one (21) of them were male and fourteen (14) were female. From these, eight (8) were Physics teachers, eight (8) were Mathematics teachers, nine (9) were Chemistry teachers, seven (7) were Biology teachers and the remaining three (3) were from Engineering discipline. 15 Headteachers were not included in the 
survey. During the training the teachers were observed and then were given the online questionnaires to respond. Teachers’ participation was voluntary

\section{$5 \quad$ Results and Discussion}

Data were collected and analysed by the STEM Kio-Kit technical team. Google form was used to collect and analyse them. The data were gathered into two main categories, the first part asked about teacher's profile with information including gender, school, subject specialization, teacher's experience and role. The second part consisted of main questions on the perception of using Kio-Kit in classroom and the challenges of using this technology with an extra space provided for any additional comments. The following were cited to depict teachers' perception on using Kio-Kit to enhance Teaching and Learning STEM subjects in Zanzibar.

\subsection{Teachers Personal Information}

In terms of gender, 35 out of 75 teachers from the 15 schools who participated the training responded, in which $60 \%$ being male and $40 \%$ were female.

The study also went further to know the teaching experience of the participants. As shown in Fig. 1. Teaching experience of STEM teachers Below, the results reveals that majority of the teachers (44\%) have experience of about 1 to 5 years in teaching, while 24\% fall under the category of 6 to 10 years of working experience, $9 \%$ of teachers have experience of 11 to 15 years while $21 \%$ among them fall under 15 to 20 years of experience and about only $2 \%$ were having more than 20 years of working experience.

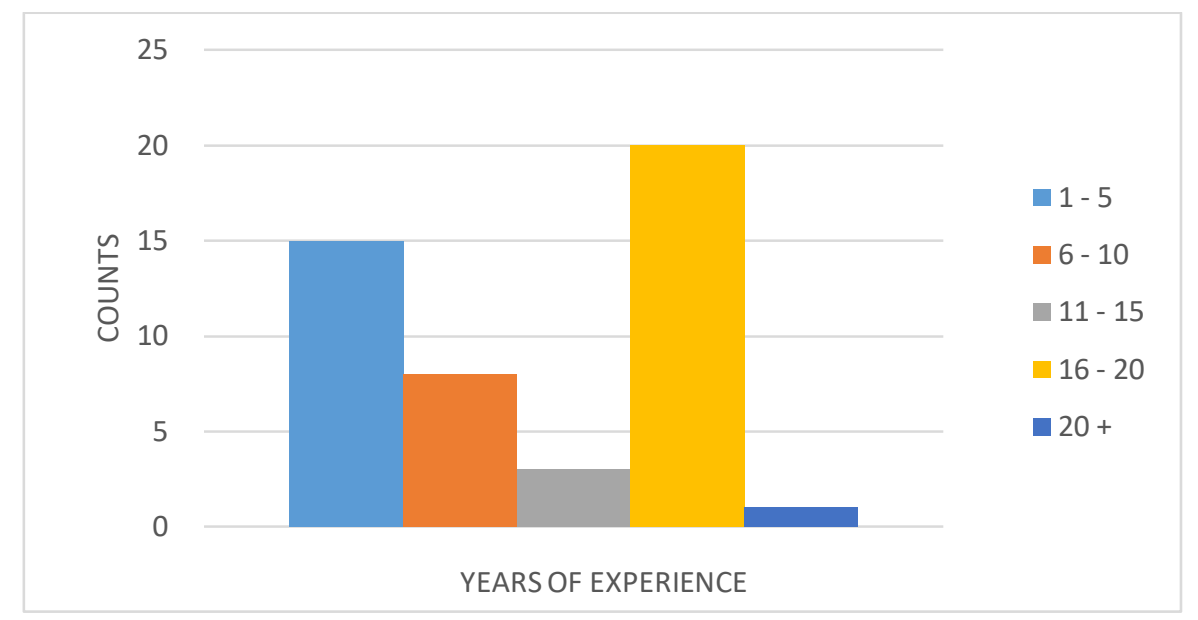

Fig. 1. Teaching experience of STEM teachers 
Moreover, the teachers were asked to mention their subjects of specialization in relation to STEM subjects. The results showed that, $21.2 \%$ of teaches Biology subject, $21.2 \%$ are Chemistry teachers, $24.2 \%$ are Physics teachers, $24.2 \%$ are Mathematics teachers and the remaining 9.1\% come from Engineering and Technology subjects.

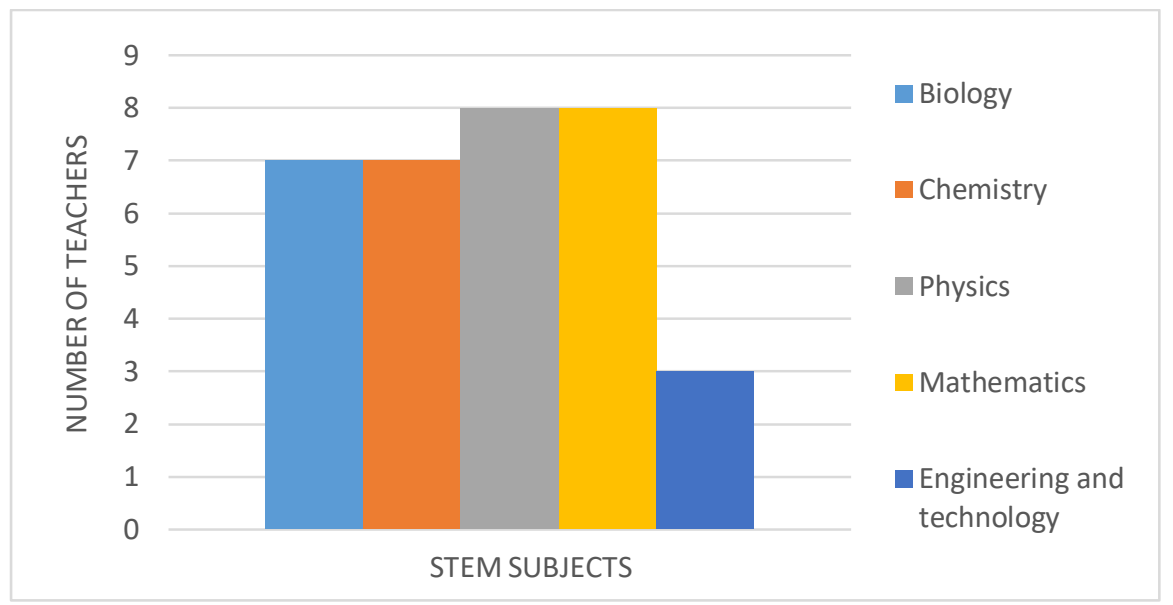

Fig. 2. Subject of Specialization of STEM Teachers

Most of the teachers who participated in the training were subject teachers (82.9\%) while only $8.6 \%$ were head teachers, $2.9 \%$ were assistant head teachers, $2.9 \%$ class teachers and the remaining $2.9 \%$ were section leaders.

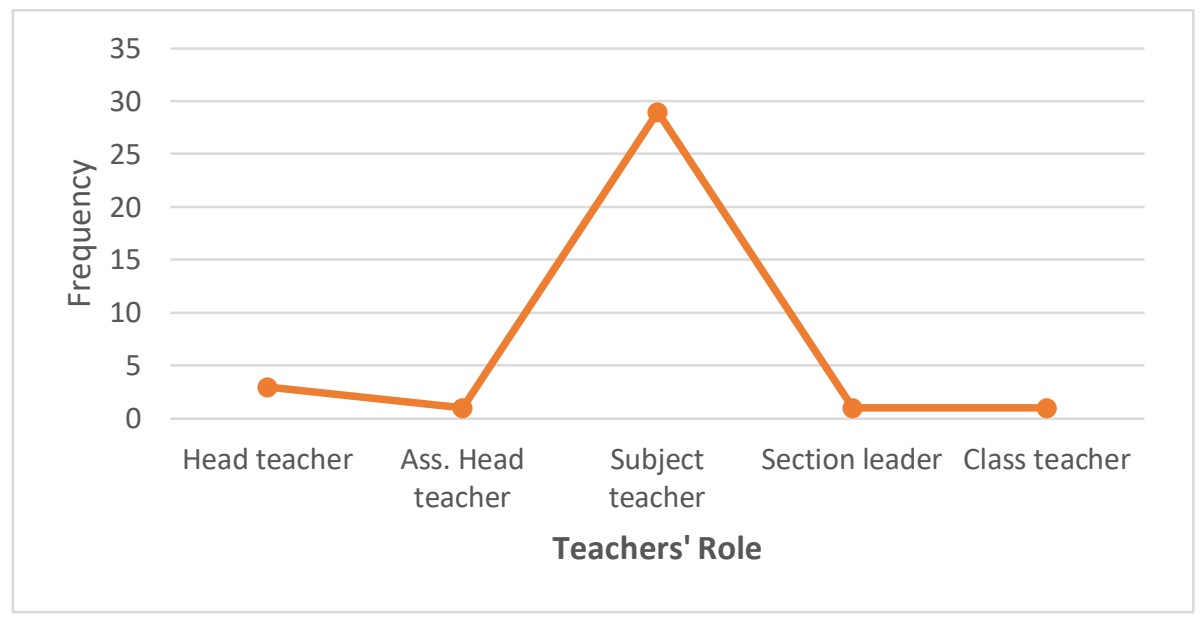

Fig. 3. Teacher's Role 


\subsection{Teachers' Perception on using Kio-Kit in Teaching and Learning}

In order to measure the perception of the teachers on the use of Kio-Kit, different criteria have been used to check the degree of their perceptions on using this new technology as shown in Error! Reference source not found.

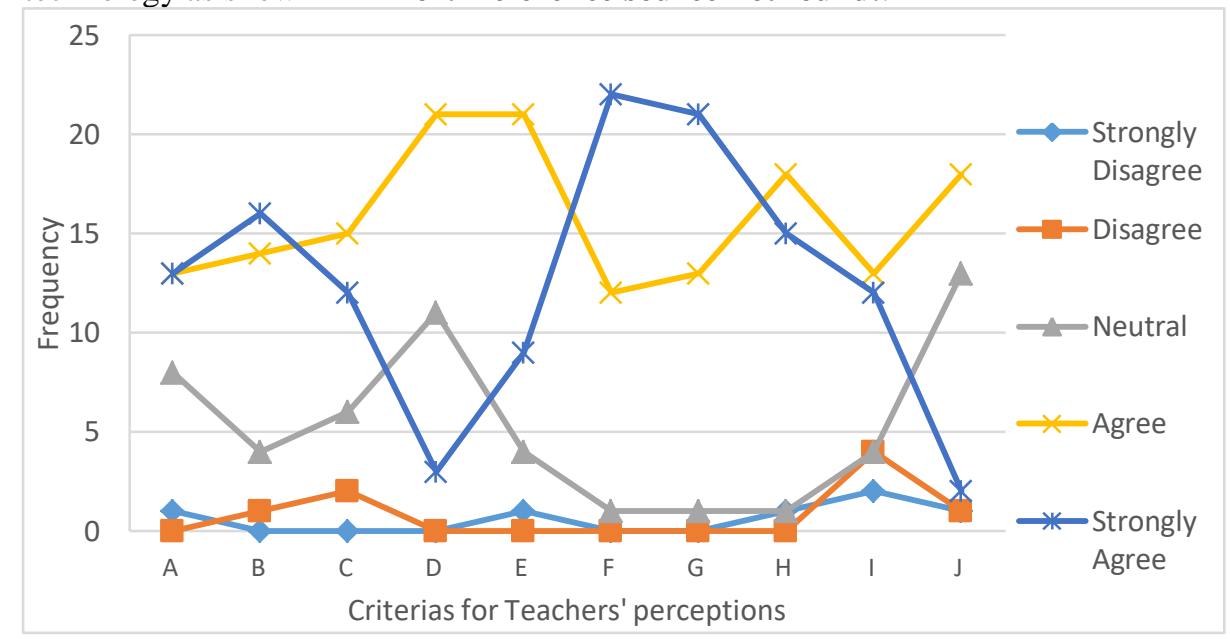

Fig. 4. Teachers' perception on the use of Kio-Kit

The perception criteria used in Error! Reference source not found. are defined using the letters as tabulated in Error! Reference source not found. below.

Table 1. Criteria used to measure Teachers' Perception on using Kio-Kit technology

\begin{tabular}{ll}
\hline Letter & Criteria \\
\hline A & Improve Students' Attendance \\
B & Improve Teachers attendance \\
C & Pedagogical Shift in classroom \\
D & Increase engagement with the local community \\
E & Improve information literacy skills in students \\
F & Increase students interaction and participation \\
G & Provide new knowledge and skills to student \\
H & Give more opportunities for students to learn \\
I & Involve all types of learners in learning process \\
J & Improve Student English literacy \\
\hline
\end{tabular}




\section{Improve Student Attendance}

Majority of the teachers agreed that the use of Kio-Kit technology in the classroom will improve students' attendance. $74.2 \%$ strongly agree on this, while only $2.9 \%$ disagree, the remaining 22.9\% were neutral. The idea is also supported by the study conducted by Marie-Anne [6] who summarised that teachers perceived a significant increase in the student engagement, student excitement as well as student acceleration of learning.

\section{Improve Teachers attendance}

$85.7 \%$ of the participants agreed that the use of Kio-Kit technology in the classroom will improve the attendance of the teachers in the class.

\section{Pedagogical Shift in Classroom}

Out of the teachers who responded, 80\% support that the use of Kio-Kit technology in classroom will transform the teaching in schools. The remaining $20 \%$ were neutral and none of them disagree on this. The use of technology in education has changed the learning process due to the introduction of new features in the pedagogy such as collaborative learning and rapid access of information. Various new learning theories have been proposed such as heutagogy and paragogy as mentioned by Anca and Cosmina [7].

\section{Increase engagement with the local community}

The findings show that $68.6 \%$ of the teachers agree that the use of Kio-Kit technology will boost students' participation in the classroom, while $31.4 \%$ of them were neutral.

\section{Improve information literacy skills in students}

Information literacy skills in students are perceived to improve by the use of Kio-Kit in the classrooms by $80 \%$ of the teachers. Only $2.9 \%$ of them disagree and the remaining $17.1 \%$ were neutral.

\section{Increase students' interaction and participation.}

Most of the teachers agree on the increase of students' interaction and paeticipation.91.4\% agree fully to this, $5.7 \%$ were neutral and only $2.9 \%$ disagree. It is obvious, as Kio-Kit like any other digital technology will provide features such as collaborative learning, multitasking as well as rapid information access.

\section{Provide new knowledge and skills to students}

The study revealed $97.1 \%$ of the teachers agree that students will gain new knowledge and skills to students, the remaining $2.9 \%$ were neutral while none of them disagree. Kay et al. [8] commented that middle and secondary students who were introduced to web-based learning tools in their classes gain a hands-on learning experience and was able to practice new skills. 


\section{Give more opportunities for students to learn}

The study also revealed that $94.3 \%$ of the teachers agree that the use of Kio-Kit in classroom will give more opportunities for the students to learn, $2.9 \%$ were neutral while $2.9 \%$ disagree.

\section{Involve all types of learners in learning process}

$71.4 \%$ of the teachers perceived that the integration of this new technology in their classes will involve all types of learners in the learning process, $11.4 \%$ of them were neutral and the remaining $17.1 \%$ disagree on the following point.

\section{Improve Student English literacy}

In this study $57.1 \%$ of the teachers agree on the improvement of student English literacy, $37.1 \%$ were neutral, $5.8 \%$ while disagree. The study made by Shao-Chia [9] exposed that all the teachers who participate in the study appreciated the use of technology in enhancing teaching and learning English due to the presence of various online materials that will enable them together with their students to cope well with this situation.

\section{Challenges of Using Kio-kit in Classroom}

In addition to the above points, the teachers were asked to mention if they may encounter any challenges in using this kind technology during their classroom. The overarching challenge for most of the teachers was on time management on introducing the lesson to class and the use of Kio-Kit. While most of them claim that it was very difficult for them to manage time as it is a new method introduced to them, others relate time management to the time it takes for the resources found in the Kio-Kit to be displayed.

Another major concern is on the large number of students in most of Unguja and Pemba Schools. The distribution of the Kio tablets will be very difficult for them since only 40 kio-tablets available, which is different from the real scenario currently facing many schools which has very large classroom and many students at a time.

Further, the teachers also mentioned that student's concentration might be another challenge, since they can concentrate on other contents apart from what the teacher wants them to view, as there is no any form of control on the teachers' side.

Other challenges mentioned including lack of teachers with competence in using current technologies, and most of them suggested more training to the teachers. Some teachers also pointed out that some teachers are resistant to use the new technologies in their classes, and they prefer the traditional way of teaching due to their experience. Most of them also mentioned about the available contents in the Kio-kit which to some extent is not relevant for the chosen group of students (Form one and Form two students). Lastly, some teachers dictate that English is a problem to most of their students, and they are afraid the students may fail to follow the given instructions and navigate through various contents available in the Kio-Kit. 


\section{Conclusion}

As we have seen above, Kio-Kit technology is one of the digital technologies that can be used in classroom to improve or enhance teaching and learning, especially in countries where there is no adequate infrastructure such as internet access and the like. Allowing young students to use current technologies afford them the opportunity to explore and giving them more opportunity to learn by themselves and improve their critical thinking skills, which are the most important skills needed in the 21st century workplace. Results from the teachers demonstrate that the use of Kio-Kit technology have many positive impacts on students' performance as well as teachers' technical know-how despite the few challenges that has been stated earlier. It is safe to argue that with some improvements, commitment and dedication, the use of this technology is of importance for the preparation of the students in the technological era.

\section{References}

1. Zolfaghari Mashhadi, V., \& Reza Kargozari, M.: Influences of digital classrooms on education. Procedia Computer Science, 3, 1178-1183. (2011). doi:10.1016/j.procs.2010.12.190.

2. Forzani, E., \& Leu, D. J. New Literacies for New Learners: The Need for Digital Technologies in Primary Classrooms. The Educational Forum, 76(4), 421-424. doi:10.1080/00131725.2012.708623. (2012).

3. Hoyles, C., Noss, R., \& Kent, P. On the Integration of Digital Technologies into Mathematics Classrooms. International Journal of Computers for Mathematical Learning, 9(3), 309-326. (2004). doi:10.1007/s10758-004-3469-4

4. Hack and Craft Homepage, https://hackandcraft.com/insights/articles/brck-kio-kitrevolutionising-education-africa/, last accessed 2019/03/14.

5. ITU News (2018, March 27).The Kio Kit: a digital learning solution engineered in Africa for the world. https://news.itu.int/the-kio-kit-african-solution-digital-learning/, last accessed 2018/02/14

6. Marie-Anne Mundy, Lori Kupczynski , Rick Kee.: Teacher’s Perceptions of Technology Use in the Schools. Sage Open 2 (2012). DOI: 10.1177/2158244012440813.

7. Anca Popovici, Cosmina Mironov.: Students' perception on using eLearning technologies. The 6th International Conference "Education Facing Contemporary World Issues", 7th 9th November 2014.

8. Kay, R., Knaack, L., Petrarca, D.: Exploring teacher's perceptions of web-based learning tools. Interdisciplinary Journal of E-Learning and Learning Objects, 5, 527-550. (2009).

9. Shao-Chia Cheng.: Teachers' perceptions on the use of digital tools in English teaching and learning, (2018). 